\title{
PERBAIKAN PROSES PERAKITAN CASE ASSEMBLY FRONT WITH WATER PUMP AND OIL PUMP PADA PERUSAHAAN AUTOMOTIVE DI KARAWANG
}

\author{
Muhamad Sayuti ${ }^{1}$ \\ ${ }^{1}$ Jurusan Teknik Industri, Fakultas Teknik dan Ilmu Komputer, Universitas Buana Perjuangan Karawang \\ Jl. HS. Ronggowaluyo Telukjambe Timur Karawang, \\ Email: muhamad.sayuti@ubpkarawang.ac.id
}

\begin{abstract}
This research was conducted on companies engaged in the automotive sector. Many automotive component products are produced by this company, one of which is the case assembly front with water pump and oil pump. There are several elements that can be observed in the assembly process of the case assembly front with water pump and oil pump, starting from the number of man power, SOP (Standard Operational Procedure), assembled components, and so on. In the assembly process, there are several things that become obstacles, both in terms of product quality or from the constraints of the machines used. The case assembly front with water pump and oil pump has its own standard time or cycle time to meet customer demands. The production process for the case assembly front with water pump and oil pump still creates NG products which cannot be forwarded to the next process. The suggestion to increase the number of workers in the 004 line assembly, which is to 4 workers, can cause productivity to decrease from $0.85 \%$ to $0.81 \%$. However, production capacity increased by $27 \%$ from the previous.
\end{abstract}

Keywords: Assembly process; cycle time; and manpower.

\begin{abstract}
ABSTRAK
Penelitian ini dilakukan pada perusahaan yang bergerak dalam bidang otomotif. Banyak produk komponen otomotif yang diproduksi oleh perusahaan ini, salah satunya adalah case assembly front with water pump and oil pump. Proses perakitan case assembly front with water pump and oil pump ada beberapa unsur yang dapat diamati yaitu mulai dari jumlah man power, SOP (Standart Operational Procedure), komponen yang dirakit, dan lain sebagainya. Dalam proses perakitannya pun ada bebarapa hal yang menjadi kendala baik dari segi kualitas produk atau dari kendala mesin yang dipakai. Perakitan case assembly front with water pump and oil pump mempunyai standart waktu atau cycle time tersendiri untuk dapat memenuhi permintaan customer. handling untuk mensuplai kebutuhan komponen yang akan dirakit. Namun tidak menutup kemungkinan jumlah pekerja di dalam line assembly 004 dapat berubah sesuai dengan kebutuhan permintaan customer. proses produksi case assembly front with water pump and oil pump masih tercipta produk NG yang tidak dapat diteruskan ke proses selanjutnya. usulan penambahan jumlah pekerja pada line assembly 004 yaitu menjadi 4 pekerja dapat menyebabkan produktivitas menurun dari 0,85\% menjadi 0,81\%. Namun kapasitas produksi naik mencapai $27 \%$ dari sebelumnya.
\end{abstract}

Kata Kunci: Proses perakitan; cycle time; dan man power.

\section{PENDAHULUAN}

Seiring berkembangnya dunia perindustrian serta semakin sengitnya persaingan antar perusahaan. Perusahaan dituntut untuk menghasilkan produk yang berkualitas. Selain dituntut untuk membuat produk yang berkualitas, perusahaan juga dituntut untuk dapat mebuat dan mengirim produk 
secara tepat waktu. Hal ini dilakukan agar dapat menjaga kepercayaan customer akan produk yang dibuat, baik dari segi kualitas maupun dari segi ketepatan waktu pada saat pengiriman produk.

Perancangan sistem kerja adalah suatu ilmu yang terdiri dari teknik-teknik dan prinsip-prinsip untuk mendapatkan rancangan terbaik dari sistem kerja yang bersangkutan (Sutalaksana, 2006). Teknikteknik dan prinsip-prinsip ini digunakan untuk mengatur komponen-komponen sistem kerja yang terdiri dari manusia dengan sifat dan kemampuannya, peralatan kerja, bahan serta lingkungan kerja sedemikian rupa sehingga dicapai tingkat efektivitas dan efisiensi yang tinggi bagi perusahaan serta aman, sehat, dan nyaman bagi pekerja. Perancangan sistem kerja yang baik akan menunjang kelancaran proses produksi pada perusahaan. Selain memberikan manfaat pada hasil produk, sistem perancangan kerja yang baik juga dapat memberikan manfaat bagi pekerja. Menurut (Ahyari, 2002), (Sayuti, 2019) "proses produksi adalah suatu cara, metode ataupun teknik menambah keguanaan suatu barang dan jasa dengan menggunakan faktor produksi yang ada". Tahapan proses produksi di PT. Aisin Indonesia Automotive :

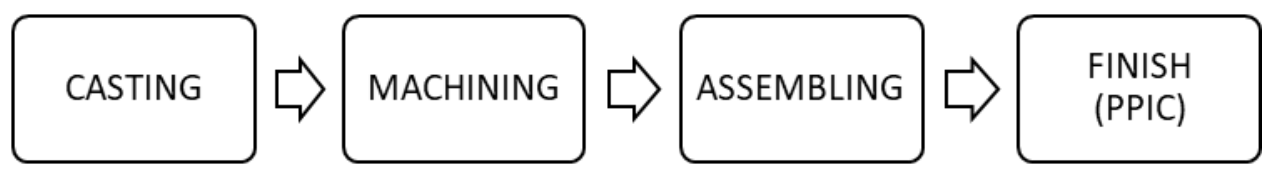

Gambar 1. Aliran Proses Produksi

\section{Casting}

Proses manufaktur yang mengunakan logam cair dan cetakan untuk menghasilkan bentuk yang mendekati bentuk akhir produk jadi. Logam cair akan dituangkan atau ditekan ke dalam cetakan yang memiliki rongga cetak sesuai dengan bentuk yang diinginkan.

\section{Machining}

Proses pembuatan benda kerja dengan menghilangkan material yang tidak diinginkan dari benda kerja dalam bentuk chip.

Assembling

Proses perakitan suatu produk yang terdiri dari beberapa komponen yang menghasil suatu fungsi produk.

Finish (PPIC)

Proses penyimpanan suatu produk jadi sebelum dikirim ke customer.

"Produktivitas adalah nilai banding antara hasil produksi dan faktor-faktor produksi yang dalam hal ini adalah peralatan dan tenaga kerja disamping modal dan sistem manajemennya sendiri. Produktivitas adalah kuantitas pekerjaan per jam tenaga kerja dan secara umum produktivitas merupakan perbandingan antara output dengan input" (Sedarmayanti, 2001). Produktivitas digunakan sebagai alat ukur atau pembanding antara hasil (output) dengan pemasukan (input). Berikut rumus yang digunakan dalam menghitung produktivitas produksi.

Produktivitas $=\frac{\text { output }}{\text { input }}$

\section{METODE PENELITIAN}

Pengamat mengambil sample waktu tiap siklus sebagai data perhitungan lalu dirata-ratakan semua datanya dengan rumus sebagai berikut :

$$
\sigma=\sqrt{\frac{\sum\left(x_{j}-\overline{\bar{x}}\right)^{2}}{N-1}}
$$

Dimana $\mathrm{N}$ adalah jumlah pengamatan pendahuluan yang telah dilakukan.Xj adalah waktu penyelesaian yang teramati selama pengukuran pendahuluan yang telah ditentukan. Setelah itu menghitung standar deviasi dari distribusi harga rata-rata subgrup dengan rumus :

$$
\sigma_{\bar{x}}=\sigma / \sqrt{N}
$$


Setelah menghitung standar deviasi dari distribusi harga rata-rata subgrup, langkah selanjutnya menghitung batas kendali atas (BKA) dan batas kendali bawah dari rata-rata data subgrup.

$$
\begin{aligned}
& \mathrm{BKA}=\overline{\bar{x}}+3 \sigma_{\bar{X}} \\
& \mathrm{BKB}=\overline{\bar{x}}-3 \sigma_{\bar{X}}
\end{aligned}
$$

Batas kendali yang dihitung adalah batas seragam tidaknya subgrup. Jika semua rata-rata subgrup sudah ada dalam batas kendali maka dapat digunakan untuk menghitung banyaknya pengukuran yang diperlukan, yaitu dengan rumus :

$$
N^{\prime}=\frac{40 \sqrt{N \cdot \sum X^{2}-\left(\sum x_{J}\right)^{2}}}{\sum x_{J}}
$$

$\mathrm{N}$ merupakan jumlah pengukuran yang telah dilakukan. Rumus ini dapat digunakan untuk 5\% tingkat ketelitian dan 95\% tingkat keyakinan. Apabila pengukuran telah dilakukan yaitu semua keseragaman telah sesuai dengan yang dikehendaki, dan sesuai dengan ketelitian dan tingkat-tingkat yang diharapkan maka pengukuran waktu dinyatakan telah selesai. Langkah selanjutnya yaitu mencari waktu baku yaitu dengan cara sebagai berikut :

$$
\mathrm{Ws}=\frac{\sum x_{j}}{N}
$$

Rumus diatas digunakan untuk menghitung waktu siklus, yaitu waktu penyelesaian rata-rata selama pengukuran.

$$
\mathrm{Wn}=\mathrm{Ws} \times \mathrm{p}
$$

Faktor penyesuaian adalah p. Perhitungan ini digunakan jika ada ketidakwajaran dari kecepatan bekerja. Dimana $\mathrm{p}=1$ jika kecepatan pekerja dianggap wajar, $\mathrm{p}<1$ jika pekerjaannya terlalu lambat, dan $\mathrm{p}>1$ jika pekerjaan dianggap cepat. Setelah menghitung waktu normal maka sampailah pada perhitungan terakhir yaitu perhitungan waktu baku.

$$
\mathrm{Wb}=\mathrm{Wn}+1
$$

1 adalah kelonggaran atau allowance dimasukan ke dalam perhitungan untuk pekerja menyelesaikan pekerjaannya disamping waktu normal. Ada tiga hal yang ada dalam kelonggaran ini yaitu menghilangkan rasa lelah atau fatigue, kebutuhan pribadi, dan gangguan-gangguan yang kerap terjadi pada saat menyelesaikan pekerjaan.

\section{HASIL DAN PEMBAHASAN}

Perusahaan automotive telah menerapkan abnormality rule untuk penanganan tiap abnormality yang terjadi. Berikut tahapan-tahapan penanganan abnormality :

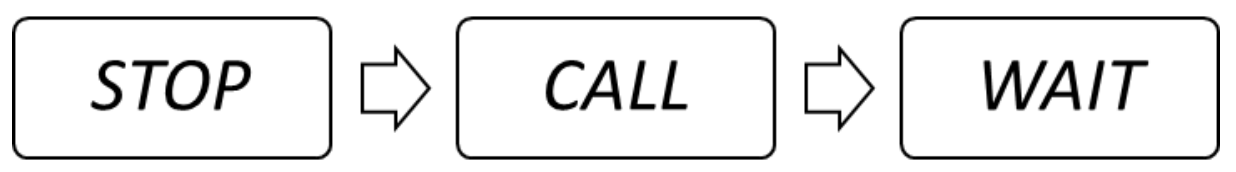

Gambar 2. Prosedur ketika menemui abnormality

1. STOP

Saat menemukan abnormality, operator harus berhenti melakukan pekerjaan.

2. CALL

Operator memanggil atasan dengan cara menekan tombol andon. Tombol andon akan berbunyi sehingga terdengar oleh atasan.

3. WAIT

Operator menunggu penanganan abnormality oleh atasan dan menunggu perintah selanjutnya.

(Effi et al., 2017) 


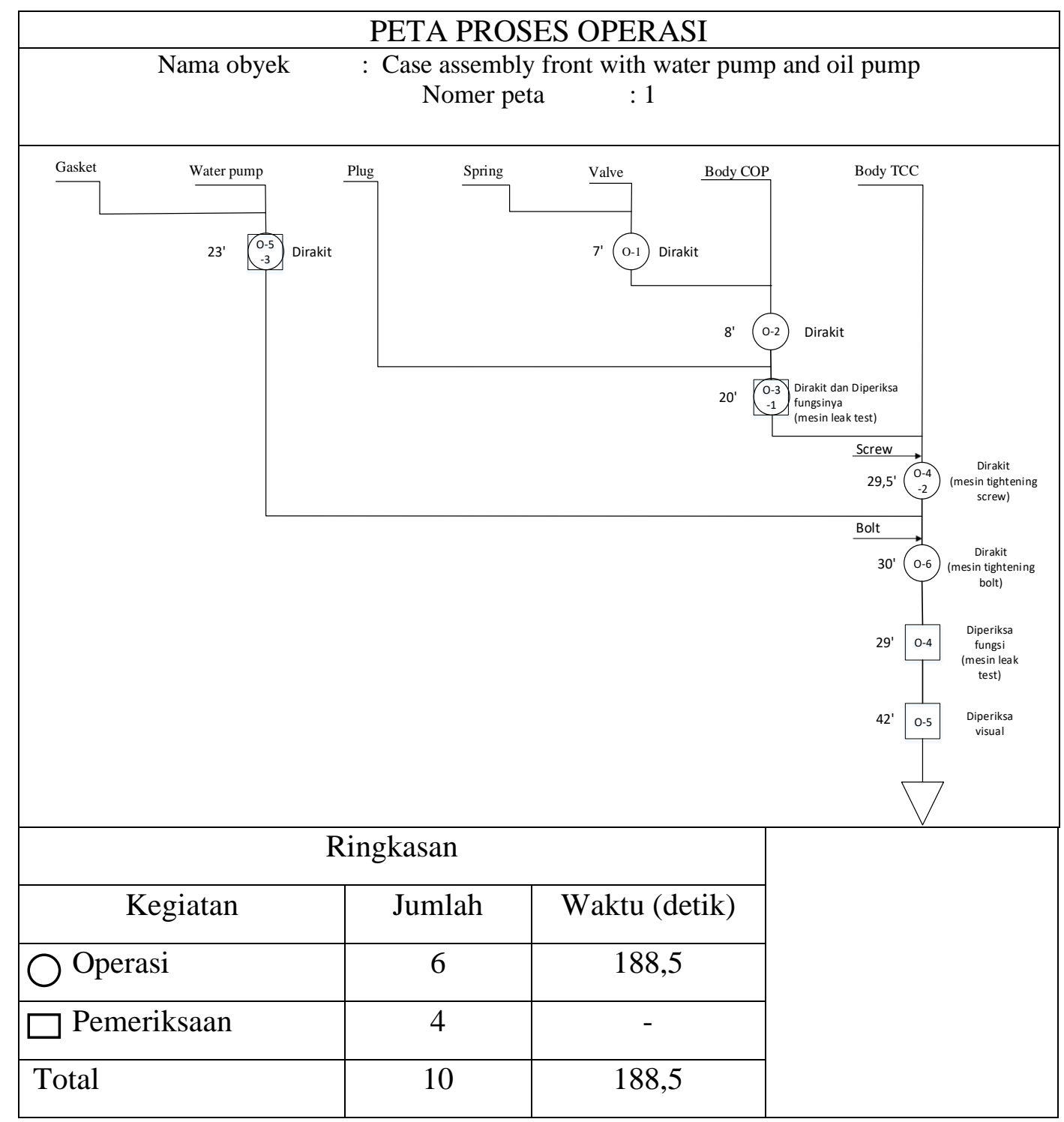

Gambar 3. Peta Proses Operasi

Tabel 1. Hasil Pengukuran Usulan

\begin{tabular}{llllll}
\hline Subgrup ke & \multicolumn{4}{l}{ Waktu penyelesaian berturut-turut } & Harga rata-rata \\
\hline 1 & 51 & 49 & 52 & 49,5 & 50,375 \\
2 & 50 & 48 & 49 & 50 & 49,25 \\
3 & 51 & 48,5 & 49,5 & 50 & 49,75 \\
4 & 48,5 & 49 & 50 & 50 & 49,375 \\
& Jumlah & & 198,75 \\
& $\overline{\bar{x}}$ & & & 49,6875 \\
\hline
\end{tabular}

Setelah mendapatkan nilai rata-rata $\bar{x}$ dari data perhitungan diatas maka dihitung standar deviasi sebenarnya dari waktu penyelesaian.

$\sigma=\sqrt{\frac{\sum\left(x_{j}-\overline{\bar{x}}\right)^{2}}{N-1}}$ 


$$
\begin{aligned}
\sigma & =\sqrt{\frac{(51-49,6875)^{2}+(49-49,6875)^{2}+(52-49,6875)^{2}+\operatorname{mammama}(50-49,6875)^{2}}{16-1}} \\
\sigma & =\sqrt{\frac{16,437504}{15}} \\
\sigma & =\sqrt{1,0958336} \\
\sigma & =1,04682071053
\end{aligned}
$$

Lalu hitung standar deviasi dari distribusi harga rata-rata subgrup.

$$
\begin{aligned}
& \sigma_{\bar{x}}=\sigma / \sqrt{N} \\
& \sigma_{\bar{x}}=1,04682071053 / 4 \\
& \sigma_{\bar{x}}=0,26170517763
\end{aligned}
$$

Setelah nilai standar deviasi dari distribusi harga rata-rata subgrup telah ditemukan, langkah selanjutnya adalah menghitung BKA dan BKB.

$$
\begin{aligned}
& \mathrm{BKA}=\overline{\bar{x}}+3 \sigma_{\bar{X}} \\
& \mathrm{BKA}=49,6875+3(0,26170517763) \\
& \mathrm{BKA}=50,47261553 \\
& \mathrm{BKA}=\overline{\bar{x}}-3 \sigma_{\bar{X}} \\
& \mathrm{BKB}=49,6875-3(0,26170517763) \\
& \mathrm{BKB}=48,90238447
\end{aligned}
$$

Perhitungan N' dibawah hanya menggunakan 10 data perhitungan yang sesuai dengan batas kendali. Perhitungan dibawah adalah untuk ketelitian 5\% dan tingkat keyakinan 95\%.

$$
\begin{aligned}
N^{\prime} & =\frac{40 \sqrt{N \cdot \sum X^{2}-\left(\sum X_{J}\right)^{2}}}{\sum x_{I}} \\
N^{\prime} & =\frac{40 \sqrt{16(24603,5)-(496)^{2}}}{496} \\
N^{\prime} & =\frac{40 \sqrt{393656-246016}}{496} \\
N^{\prime} & =\frac{40 \sqrt{147640}}{496} \\
N^{\prime} & =\frac{15.369_{a} 5803456}{496} \\
N^{\prime} & =30,98
\end{aligned}
$$

Dari data $N^{\prime}$ diatas maka untuk ketelitian dan tingkat keyakinan tersebut memerlukan pengukuran sebanyak 30,98 atau dibulatkan menjadi 31 pengukura atau kurang 15 kali pengukuran lagi.

Tabel 2. Hasil Pengukuran Usulan Tambahan

\begin{tabular}{llllllllllllllll}
\hline Pengukuran ke & 17 & 18 & 19 & 20 & 21 & 22 & 23 & 24 & 25 & 26 & 27 & 28 & 29 & 30 & 31 \\
waktu & 50 & 49 & 49,5 & 51 & 50 & 50 & 48 & 49 & 49,5 & 51,5 & 50 & 51 & 48 & 48,5 & 50 \\
\hline
\end{tabular}

Jika pengukuran telah dilakukan maka kita dapat menghitung waktu siklus dari data diatas.

$$
\begin{aligned}
\mathrm{Ws} & =\frac{\sum x_{j}}{N} \\
\mathrm{Ws} & =\frac{1540}{31} \\
\mathrm{Ws} & =49,6774 \text { detik }
\end{aligned}
$$

Lalu hitung waktu normalnya dengan perhitungan sebagai berikut :

$$
\begin{aligned}
\mathrm{Wn} & =\mathrm{Ws} \times \mathrm{p} \\
\mathrm{Wn} & =49,6774 \times 1 \\
\mathrm{Wn} & =49,6774
\end{aligned}
$$


P dianggap 1 karena kecepatan pengerjaan pekerja pada saat dilakukan pengukuran dianggap wajar sehingga $\mathrm{p}=1$. Setelah waktu normal didapat maka langkah selanjutnya adalah menghitung waktu baku dengan perhitungan sebagai berikut :

$$
\begin{aligned}
& \mathrm{Wb}=\mathrm{Wn}+1 \\
& \mathrm{~Wb}=49,6774+1 \\
& \mathrm{~Wb}=50,6774
\end{aligned}
$$

Waktu baku dari data perhitungan diatas adalah 50,6774 atau dapat dibulatkan kebawah menjadi 50,5.

Dengan berubahnya kapasitas produksi yang disebabkan oleh berubahnya cycle time. Maka produktivitas dari hasil produksipun akan berubah. Berikut perhitungan produktivitas produksi line assembly 004.

a. Perhitungan produktivitas sekarang

$$
\begin{aligned}
\text { Produktivitas } & =\frac{\text { output }}{\text { input }} \\
& =\frac{381 \text { pes }}{3 \text { operator } x 6,73 \text { jam } x 22 \text { hari }} \\
& =0,85 \%
\end{aligned}
$$

b. Perhitungan produktivitas usulan

$$
\begin{aligned}
\text { Produktivitas } & =\frac{\text { output }}{\text { input }} \\
& =\frac{484 \text { pes }}{4 \text { operator } x 6,73 \text { jam } x 22 \text { hari }} \\
& =0,81 \%
\end{aligned}
$$

Hasil diatas menunjukan penambahan jumlah pekerja produksi di line assembly 004 dari tiga pekerja menjadi empat pekerja menyebabkan produktivitas menurun dari $0,85 \%$ menjadi $0,81 \%$. Namun kapasitas produksi menjadi meningkat $27 \%$ dengan ditambahnya jumlah pekerja menjadi empat pekerja produksi di line assembly 004.

\section{KESIMPULAN}

Line assembly 004 merupakan salah satu line perakitan produk yang ada di PT. Aisin Indonesia automotive yang memproduksi case assembly front with water pump and oil pump yaitu salah satu komponen yang ada di dalam mesin mobil. Case assembly front with water pump and oil рump merupakan gabungan dari dua fungsi produk yaitu oil pump dan water pump. Oil pump bekerja memompa oil yang ada di pump secara beraturan dengan volume yang tepat. Oil pump ini berfungsi mengurangi gesekan mesin dan mengurangi keausan yang ada di mesin mobil dengan cara mensuplai oil. Selain oil pump di dalam case assembly front with water pump and oil pump juga terdapat water pump. Water pump berfungsi sebagai penjaga kestabilan temperatur engine dan bagian yang mensirkulasi cooling water yang ada di dalam engine.

Dalam proses perakitan case assembly front with water pump and oil pump membutuhkan empat mesin yaitu dua mesin leak tester untuk memeriksa tekanan komponen cover oil pump dan tekanan produk jadi case assembly front with water pump and oil pump, mesin tightening screw yang dipergunakan untuk memasang cover oil pump, dan mesin tightening bolt yang digunakan untuk memasang water pump. Untuk memenuhi permintaan customer terhadap produk case assembly front with water pump and oil pump, line assembly 004 membutuhkan empat tenaga kerja yaitu tiga orang pekerja perakitan dan satu orang pekerja material handling untuk mensuplai kebutuhan komponen yang akan dirakit. Namun tidak menutup kemungkinan jumlah pekerja di dalam line assembly 004 dapat berubah sesuai dengan kebutuhan permintaan customer. 
Dalam proses produksi case assembly front with water pump and oil pump masih tercipta produk NG yang tidak dapat diteruskan ke proses selanjutnya. Dalam usulan penambahan jumlah pekerja pada line assembly 004 yaitu menjadi 4 pekerja dapat menyebabkan produktivitas menurun dari $0,85 \%$ menjadi $0,81 \%$. Namun kapasitas produksi naik mencapai $27 \%$ dari sebelumnya.

\section{DAFTAR PUSTAKA}

Ahyari, A. (2002). Manajemen Produksi dan Pengendalian Produksi. Yogyakarta, BFE.

Effi, L., Wiratnoa, S. E., Anggrahinia, D., \& Hakimb, M. S. (2017). Pemetaan Proses Bisnis dengan Pendekatan Klasifikasi Proses CIMOSA: Studi Kasus Perusahaan Pengelola Kawasan Industri. Jurnal Sisfo Vol. 06 No. 03 (2017) i-Ii, 06(03).

Sayuti, M. (2019). Penentuan Kapasitas Produksi Untuk Meningkatkan Produktivitas Kerja Pada IKM Semprong Di Kabupaten Karawang. Industry Xplore - Vol. 04 No. 01, Agustus 2019, 04(01).

Sedarmayanti, M., \& Pd, M. (2001). Sumber daya manusia dan produktivitas kerja. Bandung: CV. Mandar Maju.

Sutalaksana, I. Z., Anggawisastra, R., \& Tjakraatmadja, J. H. (2006). Teknik perancangan sistem kerja. Bandung: ITB. 